City University of New York (CUNY)

CUNY Academic Works

International Conference on Hydroinformatics

2014

Comparison Of Various Phased Approaches For The Constrained

Minimum-Cost Design Of Water Distribution Networks

Enrico Creaco

Marco Franchini

Tom Walski

How does access to this work benefit you? Let us know!

More information about this work at: https://academicworks.cuny.edu/cc_conf_hic/39

Discover additional works at: https://academicworks.cuny.edu

This work is made publicly available by the City University of New York (CUNY).

Contact: AcademicWorks@cuny.edu 
$11^{\text {th }}$ International Conference on Hydroinformatics

HIC 2014, New York City, USA

\section{COMPARISON OF VARIOUS PHASED APPROACHES FOR THE CONSTRAINED MINIMUM-COST DESIGN OF WATER DISTRIBUTION NETWORKS}

ENRICO CREACO (1), MARCO FRANCHINI (2), TOM WALSKI (3)

(1): Dipartimento di Ingegneria, Università degli Studi di Ferrara, Via Saragat, 1, 44100

Ferrara. E-mail: enrico.creaco@unife.it

(2): Dipartimento di Ingegneria, Università degli Studi di Ferrara, Via Saragat, 1, 44100 Ferrara.E-mail: marco.franchini@unife.it

(3): Bentley Systems, Incorporated, 3 Brian's Place, Nanticoke, PA 18634. E-mail: Tom.Walski@bentley.com

\section{EXTENDED ABSTRACT}

Network design is one of the most investigated topics in the scientific literature of water distribution systems. Starting from the late seventies [1], numerous single objective ([2], [3], [4], [5], [6] to name a few) and multi-objective ([7], [8], [9], [10], [11] to name a few) algorithms have been proposed. Though being worthwhile contributions to the field, most of the proposed algorithms were developed laying on the restrictive assumptions that design is performed 'statically' and all the construction is done in a single phase such that there is no gradual growth/build-out in the system. Generally, in the static design, reference is made to the expected final layout (see Figure 1 as an example) and peak demand at the end of the construction life. These assumptions render the algorithms inconsistent with the design methods usually adopted by practitioners who instead operate following the water network natural expansion, which takes place in phases (see Figure 2 as an example). As a matter of fact, this single step design approach could lead to the installation of exceedingly large pipes, oversized with respect to the network growth really occurring in the future, and then to exceedingly large investments at the beginning of the construction.

Recently, some studies ([12], [13], [14], [15]) attempted to produce new multi-objective algorithms (cost minimization plus reliability maximization), aimed at conceiving network design dynamically and in phases, in a bid to follow the real expansion of urban centres. The algorithms proposed by [12] and [13], [14] make it possible to optimize all the construction steps inside a certain temporal horizon simultaneously while producing a Pareto front. In particular, [13] showed that resorting to phasing of construction in the context of network design yields some advantages, in that:

- $\quad$ it allows engineers to design the short term upgrades, which are supposed to guarantee a prefixed level of reliability, while keeping an idea of the long term network growth and expansion; 
- $\quad$ for long time horizons, it turns out to be cost effective; in fact, by partially deferring construction, the community is able to put aside resources which can be more effectively allocated to alternative uses.

[12] and [14] proposed algorithms able to consider the uncertainty in network demand growth inside the phasing of construction approach. With respect to the algorithm proposed by [12], the algorithm of [14] has the advantage of being able to take account of the network layout growth in time, though the latter growth was dealt with deterministically. The main conclusion of the work of [14] was that considering uncertainty leads to the network being sized more conservatively, especially in the first steps, in order to render network construction more flexible to adapt itself to various conditions of demand growth over time.

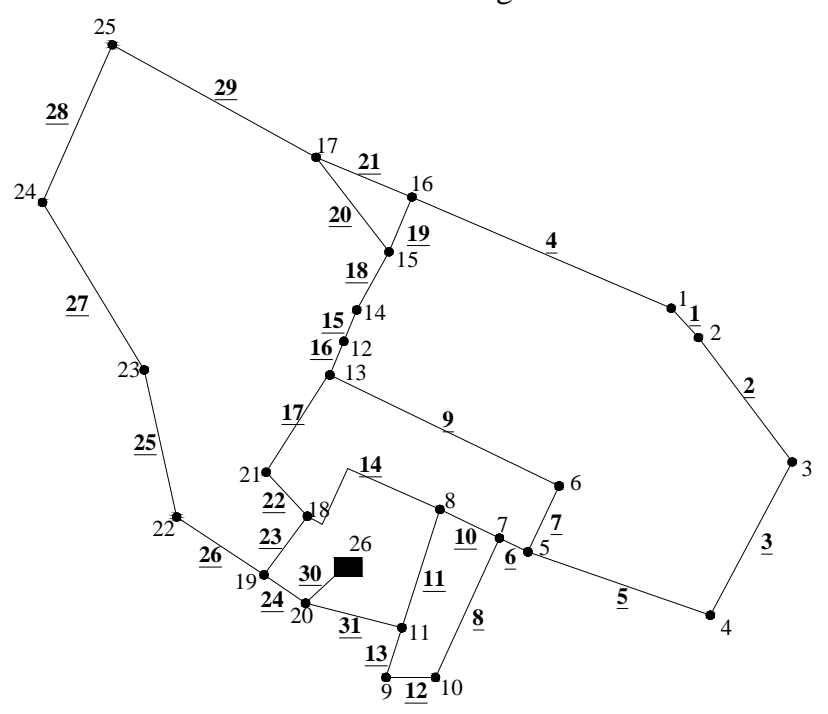

Figure 1. Network considered in its full extension at the end of the construction life.

Though the recent studies of [12] and [13], [14] have the undisputed merit of presenting a more realistic version of network design, based on phasing of construction, they limit themselves to planning the whole construction design at the beginning of the construction life and do not then consider the fact that in practical applications the construction design is indeed corrected at the end of each time step, in order to upgrade both the current and the projected network demands on the basis of the demand growth actually observed in the past.

The aim of the present work is then to analyze 1) the extent to which the network design based on phasing of construction is affected by repeating the design at the beginning of each phase while upgrading the forecasted future demand growth, 2) the value of basing design on a long term vision and 3) the downside of optimizing a system based on a short term vision. 


\section{years 0-20}

$$
24
$$

\section{years 20-40}

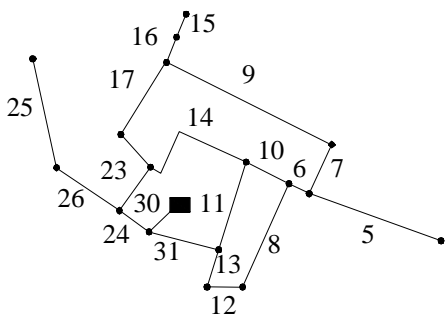

years $40-60$

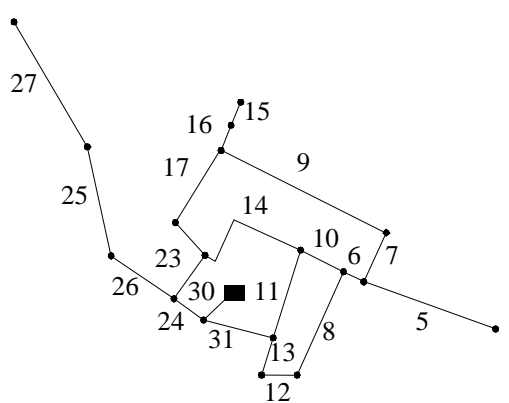

\section{years 60-80}

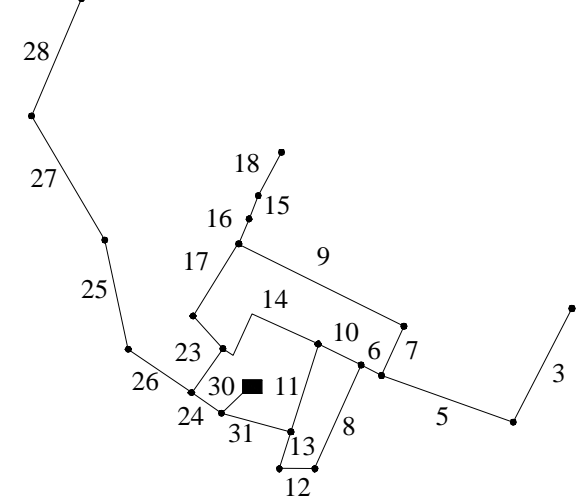

\section{years 80-100}

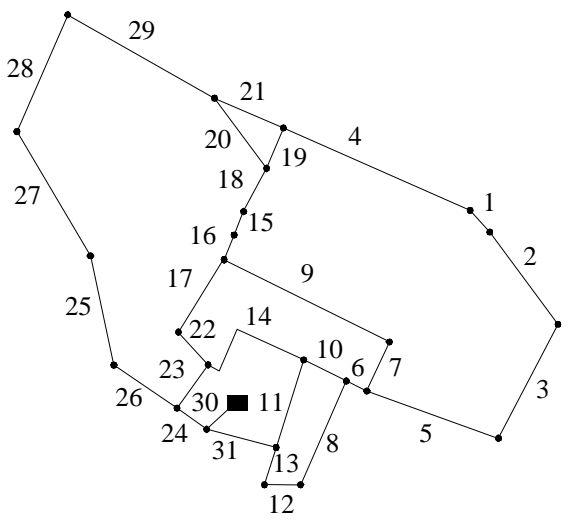

Figure 2. Phases of the expansion of the network.

In order to accomplish the task, three approaches for the design of the main skeleton of a water distribution network were analyzed and compared. These approaches consider the different phases of construction of the water network and the spatial and temporal variation in the demand growth rate. However, the first approach considers one phase at a time and the growth demand rate prediction is performed on the basis of the last value actually observed during the previous phase in the already constructed network; the second approach considers all the phases simultaneously but it performs the design only once at the initial time instant by using the predicted growth demand rates without upgrading them as time goes by; like the first approach, the third and last approach repeats the design at the beginning of each phase, but, like the second approach, it considers all the remaining phases simultaneously, while the estimates of the future growth demand rates are updated on the basis of the actually values observed.

The designs determined by each approach were evaluated against 100 scenarios. 
In general, the approach of designing in phases for the long term resulted in lower costs and greater ability to respond to uncertainty in demand forecasts. In fact, the results of the comparison showed that using demand feedback for demand projection reduces the likelihood of pressure deficits in the network in the various construction steps and that using a long term multi-step design instead of the single-step design makes it possible to reduce the overall present worth cost of the construction. As a consequence of this, the multi-step design with the demand feedback results as the most reliable because it reduces the likelihood of pressure deficits in the various network construction steps as well as the overall present worth construction costs. At the same time, attempting to minimize costs for a short term planning horizon (approach one) virtually guarantees that the selected pipe sizes will be sub-optimal.

\section{REFERENCES}

[1] Alperovits E. and Shamir U., "Design of optimal water distribution systems”, Water Resour. Res., Vol. 13, No. 6, (1977), pp 885-900.

[2] Fujiwara O., Jenchaimahakoon B. and Edirisinghe N.C.P., "A modified linear programming gradient method for optimal design of looped water-distribution networks", Water Resour. Res., Vol. 23, No. 6, (1987), pp. 977-982.

[3] Savic D.A. and Walters G.A., "Genetic algorithms for least-cost design of water distribution networks”, J. Water Resour. Plng. and Mgmt., Vol. 123, No. 2, (1997), pp 67-77.

[4] Eusuff M.M. and Lansey K.E., "Optimization of water distribution network design using the shuffled frog leaping algorithm”, J. Water Resour. Plng. and Mgmt., Vol. 129, No. 3, (2003), pp 210-225.

[5] Krapivka A. and Ostfeld A., "Coupled Genetic Algorithm-Linear Programming Scheme for Least-Cost Pipe Sizing of Water-Distribution Systems”, J. Water Resour. Plng. and Mgmt., Vol. 135, No. 4, (2009), pp 298-302

[6] Haghighi A., Samani H.M.V. and Samani Z.M.V., "GA-ILP Method for Optimization of Water Distribution Networks”, (2011), Water Resour. Manage., Vol. 25, pp 1791-1808.

[7] Gessler J. and Walski T.M., “Water distribution system optimization”, US Army Corps of Engineers' Waterways Experimentation Station, Technical Report TREL-85-11, Vicksburg, (1985).

[8] Todini E., "Looped water distribution networks design using a resilience index based heuristic approach”, Urban Water Journal, Vol. 2, No. 3, pp 115-122.

[9] Prasad T.D., Sung-Hoon H. and Namsik P., "Reliability based design of water distribution networks using multiobjective genetic algorithms", KSCE Journal of Civil Engineering, Vol. 7, No. 3, (2003), pp 351-361.

[10] Bentley Systems, “WaterGEMS”, Bentley Systems, Exton, PA, USA, (2006).

[11] Creaco E. Franchini M., "Fast network multi-objective design algorithm combined with an a-posteriori procedure for reliability evaluation under various operational scenarios", Urban Water Journal, Vol. 9, No. 6, (2012), pp 385-399.

[12] Basupi I. and Kapelan Z., "Flexible Water Distribution System Design under Future Demand Uncertainty”, J. Water Resour. Plng. and Mgmt., in press, doi: 10.1061/(ASCE)WR.1943-5452.0000416 (Oct. 11, 2013). 
[13] Creaco E., Franchini M. and Walski T.M., "Accounting for phasing of construction within the design of water distribution networks”, J. Water Resour. Plng. and Mgmt., in press, doi: 10.1061/(ASCE)WR.1943-5452.0000358.

[14] Creaco E., Franchini M. and Walski T.M., “Taking Account of Uncertainty in Demand Growth When Phasing the Construction of a Water Distribution Network”, J. Water Resour. Plng. and Mgmt., in press, doi: 10.1061/(ASCE)WR.1943-5452.0000441, ASCE (ISSN: 07339496).

[15] Walski, T.M. (2013) “Long-term Water Distribution Design,” World Environmental and Water Resources Congress 2013, ASCE, Reston, Va. 